\title{
On-line evaluating the SS removals for chemical coagulation using digital image analysis and artificial neural networks
}

\author{
R.-F. Yu
}

Received: 2 February 2012/Revised: 4 May 2012/Accepted: 25 September 2012/Published online: 12 August 2014

(C) Islamic Azad University (IAU) 2014

\begin{abstract}
Chemical coagulation is one of the most important processes for industrial wastewater treatment plants to remove the suspended solids (SS), which depend significantly on particle characteristics. A digital image analysis system was set up in this study for the on-line measurements of particle characteristics, including particle size distribution, equivalent diameter, total area, total volume, and the fractal dimension in the both coagulation and flocculation periods in chemical coagulation. Two real industrial wastewaters, textile wastewater and landfill leachate, were used for conducting the coagulation and flocculation processes with different polyaluminum chloride dosages in a batch reactor. The artificial neural network (ANN) models were used to construct the correlations between the monitoring data acquired and the SS removal efficiencies. The experimental results indicated that the ANN models were able to precisely predict the SS removal efficiencies and effluent SS concentration after the chemical coagulation, with the correlation coefficient $\left(R^{2}\right)$ of 0.96-0.97 for real landfill leachate and $R^{2}$ of 0.93-0.97 for real textile wastewater, which provided significant benefits for the control of chemical coagulation.
\end{abstract}

Keywords Artificial neural network - Chemical coagulation and flocculation - Digital image analysis . Particle size distribution - Suspended solids · Fractal dimension

R.-F. Yu ( $\square)$

Miao-Li 360, Taiwan, Republic of China

e-mail: rfyu@nuu.edu.tw

\section{Introduction}

Chemical coagulation and sedimentation is one of the most commonly used processes to remove suspended solids (SS), organic compounds, color, and toxic materials from industrial wastewater (Merzouk et al. 2011; Theepharaksapan et al. 2011; Veli et al. 2008). When chemical coagulation is used for particle separation in wastewater treatment plants, particle size distribution and the morphology of the suspended particles are the critical parameters that affect the efficiency of the solid-liquid separation process (Grijspeerdt and Verstraete 1997; Wilen and Balmer 1999; Schmid et al. 2003; Liao et al. 2006). Conventionally, laser particle-size analyzers have been used to measure the particle size distribution during chemical coagulation (Williams et al. 2007). However, this measurement was typically conducted in a laboratory using a batch-type method, so on-line or in situ application of laser particle-size analyzers had serious limitations and operational problems. The laser particle-size analyzer is also expensive and difficult to maintain (Snidaro et al. 1997).

The photometric dispersion analyzer (PDA) was developed by Gregory (1985) to measure particle size and for use in coagulation control (Huang and Chen 1996; Kan and Huang 1998). However, this method had problems with the reliability of signals (Jarvis et al. 2005) and on-line applications (Burgess et al. 2002). An on-line nephelometric turbidimeter was developed to measure the average particle/floc size during the coagulation process by calculating the standard deviation (SD) of measured turbidity data. The SD was found to be proportional to the square root of the floc size (Cheng et al. 2008). However, none of the above methods are capable of measuring particle size and morphology simultaneously. 
Digital image analysis (DIA) has been used extensively in many industrial applications. Recently, DIA has been used in the wastewater treatment industry for different purposes, e.g., for process control due its economic advantages and for on-line monitoring due to its ease of use for this purpose. The on-line uses of DIA have included monitoring the true color of wastewater ( $\mathrm{Yu}$ et al. 2005), characterizing floc size distribution (Govoreanu et al. 2004), determining the structure of sludge flocs (Liao et al. 2006), and evaluating the settling efficiencies of various flocs (Grijspeerdt and Verstraete 1997). In our previous study, an on-line DIA system was set up to measure particle size distribution and morphology simultaneously in wastewater. The particle size distribution measured by the DIA method was very close to that measured with the laser particle size analyzer, and, by combining the DIA measurement results with an artificial neural network (ANN), the concentrations of SS in various sample could be predicted precisely ( $\mathrm{Yu}$ et al. 2009).

For chemical coagulation to remove the SS in industrial wastewater treatments, both of the laser particle-size analyzers and photometric dispersion analyzer are difficult to be applied for on-line process control. The on-line DIA device has be used to capture and measure the characteristics of suspended particles or flocs in chemical coagulation, which may help the control of chemical coagulation. In this study, a high-magnification micro-lens combined with a high-resolution charge-coupled device (CCD) were used to on-line monitor the variations of the characteristics of particles and flocs during the coagulation and flocculation of two real industrial wastewaters. The ANN models were also used to analyze the monitoring data that were acquired, including particle size distribution, equivalent diameter (ED), gray level, total area, total volume, and the fractal dimension to evaluate the SS removal efficiencies, which can be benefits for the control of chemical coagulation.

\section{Materials and methods}

\section{Reactor and DIA device}

Figure 1 is a schematic diagram of the coagulation reactor and the DIA device used in this study. A modified, batchtype reactor with a mechanical mixer, which had an effective volume of $3.6 \mathrm{~L}$, was used for chemical coagulation and flocculation. A 2-cm-wide arc and salient window was designed and connected to the reactor so that the DIA system could capture the image of the particles in the wastewater samples during coagulation and flocculation. In the DIA device, a high-magnification micro-lens with a

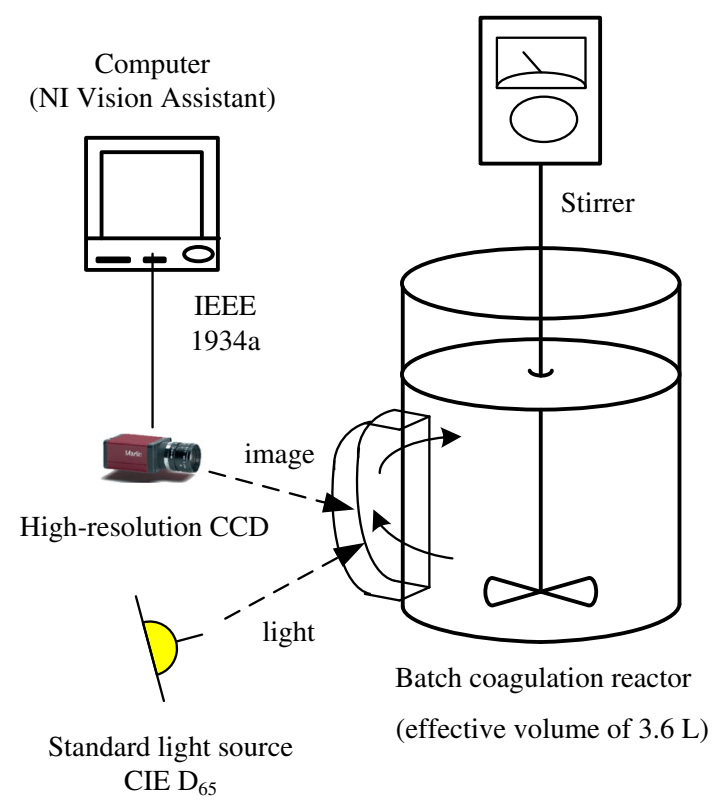

Fig. 1 Schematic diagram of the coagulation reactor and the DIA device used in this study

high-resolution CCD (Marlin F-080C, German) was used, and a halogen illuminator (LSH-150F) with an intensity of $25 \mathrm{~W} / 120 \mathrm{~V}$ was used as the light source.

\section{Experiments}

Textile wastewaters and landfill leachates always contain large amounts of SS, which typically are removed by chemical coagulation; therefore, these two industrial wastewaters were chosen for use in this study. The real wastewater samples were acquired from the influent of two full-scale, wastewater treatment plants in Miao-Li City, Taiwan. After the prepared wastewater sample was placed in the reactor, different doses of polyaluminum chloride (PAC) coagulant (Panreac, Spain) were added to the reactor. The durations for the coagulation (rapid mixing at $100 \mathrm{rpm}$ ) and flocculation (slow mixing at $30 \mathrm{rpm}$ ) processes were $100 \mathrm{~s}$ and $25 \mathrm{~min}$, respectively. For each coagulation and flocculation process, images of the particles were captured every $5 \mathrm{~s}$ for coagulation period, and $10 \mathrm{~s}$ for flocculation period, respectively; thus, a total of 170 images were captured by the CCD. Due to the variations on the characteristics of particles are relatively slow in the flocculation period, every five data were averaged in this period. The captured images were analyzed using the software program NI Vision Assistant (National Instruments, USA) in order to identify the particles. Figure 2 presents the detailed image analysis process used for the images. Typically, six processes were applied to identify each particle in captured image. After the image was 


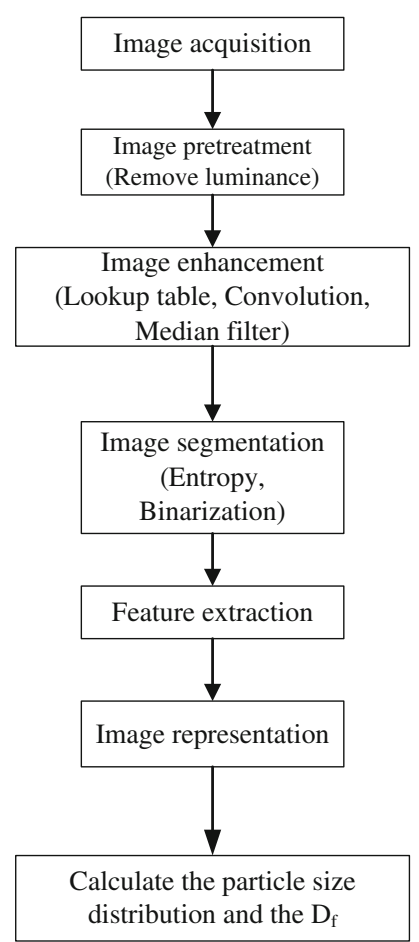

Fig. 2 Details processes of the image analysis

acquitted, the luminance of image was removed as the main pretreatment process; then, the image was enhanced by using lookup-table, convolution, and median filter methods. Image segmentation using the entropy as the threshold was used to separate and identify each particle in the image.

By using the NI Vision Assistant, the equivalent diameter (ED) of each particle in the captured image can be calculated based on the "Projected Area Diameter" method, which means the diameter of a theoretical circle containing the same projected area as the irregular particle. The mean gray value and fractal dimension $\left(D_{\mathrm{f}}\right)$ of each image also were calculated simultaneously. The SS concentrations of raw wastewater and effluent (after $30 \mathrm{~min}$ of sedimentation) for each run were measured using the method of 2540D in Standard Methods (APHA et al. 2005).

\section{Results and discussion}

Variations of particle size during coagulation and flocculation

One of the main functions of chemical coagulation is to enlarge the particle size to enhance the solid-liquid separation efficiency by adding coagulants and providing proper mixing (McGhee 1991) Therefore, variations of particle size in coagulation and flocculation processes are 
critical for SS removal efficiencies, which were monitored on-line by the DIA system in this study. Table 1 summarizes the operating conditions, monitoring data, and the influent and effluent SS concentrations for the chemical coagulation experiments conducted in this study. For influent SS concentrations of 70.0-474.5 and 41.0-110.7 $\mathrm{mg} / \mathrm{L}$ for the landfill leachate and the textile wastewater, the PAC coagulant doses were 3-330 and 10-101 mg/L, respectively. The SS removal efficiencies were 2.5-99.4 and 5.0-87.4\% for the landfill leachate and textile wastewater, respectively.

Figure 3 shows the typical characteristics of the particles detected in the images before and after coagulation and flocculation. Most particles in the image were identified clearly, and the particles were enlarged significantly after coagulation and flocculation. The ED of every particle can be calculated using the NI Vision Assistant software. It was found that particle size increased significantly after flocculation, especially in the initial period of flocculation. Figure 4 shows the typical variations of mean ED of the particles detected in each image during coagulation and flocculation. The particle sizes of wastewater samples before coagulation had EDs in the range of 50-80 $\mu \mathrm{m}$. Significant increases in the particle sizes were found after

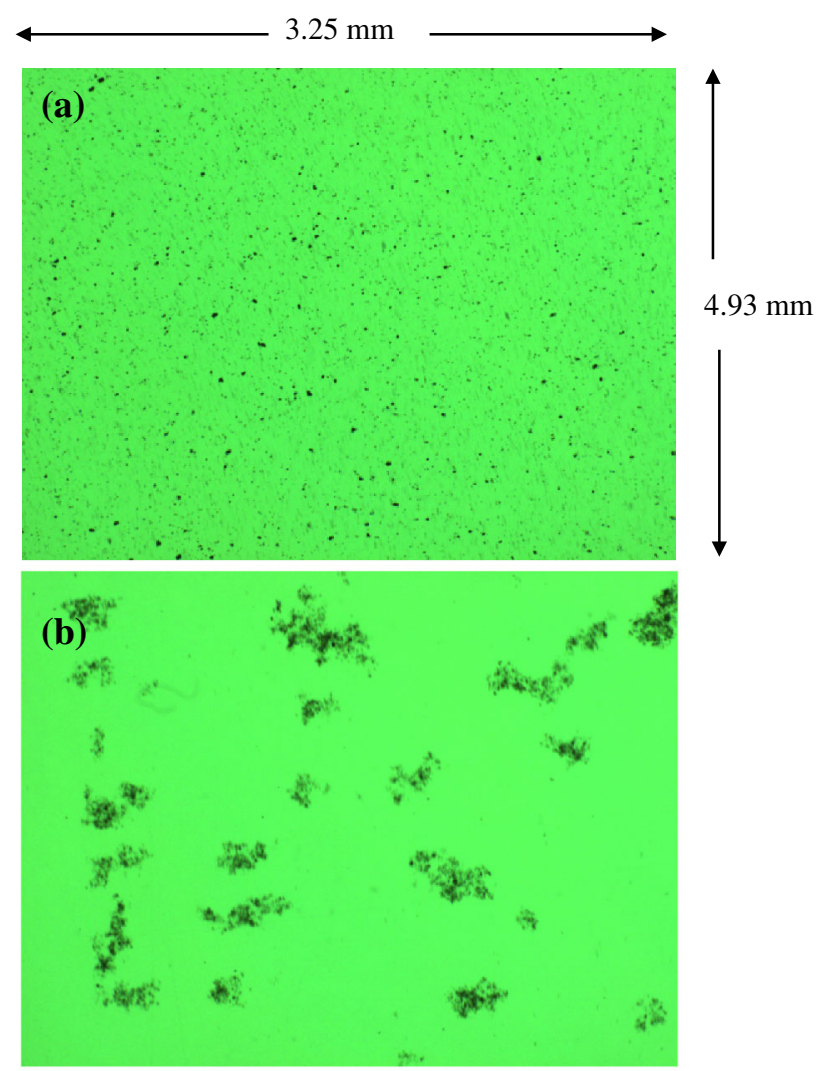

Fig. 3 Typical particles in the detected image of the DIA system before (a) and after (b) the coagulation and flocculation processes addition of the PAC coagulant after 1 min of rapid mixing and 25 min of slow mixing. For the landfill leachate, the mean $\mathrm{ED}$ of the particle increased from $6-80$ to $110-120 \mu \mathrm{m} \quad(\mathrm{PAC}=40 \mathrm{mg} / \mathrm{L}) \quad$ and $\quad 140-150 \mu \mathrm{m}$ $(\mathrm{PAC}=70 \mathrm{mg} / \mathrm{L})$ after flocculation. On the other hand, more significant increases on mean EDs were found for textile wastewater. For the textile wastewater samples, the mean ED of the particle increased from about $100 \mu \mathrm{m}$ to about $340 \mu \mathrm{m}(\mathrm{PAC}=33 \mathrm{mg} / \mathrm{L})$ and increased to about $430 \mu \mathrm{m}(\mathrm{PAC}=63 \mathrm{mg} / \mathrm{L})$. After flocculation, the average ED of the particles for the landfill leachate was $147.5 \mu \mathrm{m}$, whereas it was about $389.2 \mu \mathrm{m}$ for the textile wastewater (Table 1). This finding indicates that the increases of particle EDs are various with different types of particles.

It was also noted that the mean EDs of the particles for both the landfill leachate and the textile wastewater remained stable after $600 \mathrm{~s}$ of coagulation and flocculation. This result indicated that the required contact time for flocculation, from the standpoint of the achievable particle size, can be reduced to around 10-15 $\mathrm{min}$.

Variations of total area and total volume of particles during coagulation and flocculation

The parameters of total area and total volume of particles are two similar factors were used to present or simulate the thinking of "solids flux," which also simulate the total mass or number of particles in this study. For two wastewater samples which have similar EDs, but different total areas, the sample has large total area of particles will present higher SS removal efficiency. The total area of the particles is the summation of the area of each indentified particle in the capture image, which can be calculated using the NI Vision software. The volume of each particle was calculated base on the assumption that all the particles are spherical; thus, the volume of each particle can be also calculated using the NI Vision software, and the total volume is the summation of the volume of each indentified particle in the capture image.

Figure 5 shows the variations of total area and total volume of the particles detected in the images during coagulation and flocculation with different doses of the PAC coagulant. The total area of the particle in the images was determined using the NI Vision software, and the total volume of the particles was calculated based on the ED that was determined. The total area of the particles increased from around $1.0-2.0 \times 10^{6}$ to $2.0-5.0 \times 10^{7} \mu \mathrm{m}^{2}$ for the landfill leachate and from $1.0-2.0 \times 10^{6}$ to $2.0-4.8 \times$ $10^{7} \mu \mathrm{m}^{2}$ for the textile wastewater after coagulation and flocculation. On the other hand, the total volume of the particles increased from $2.0-6.0 \times 10^{7}$ to $0.1-2.5 \times$ $10^{10} \mu^{3}$ and to $1.2-4.8 \times 10^{10} \mu^{3}$ for the landfill leachate and the textile wastewater, respectively. 

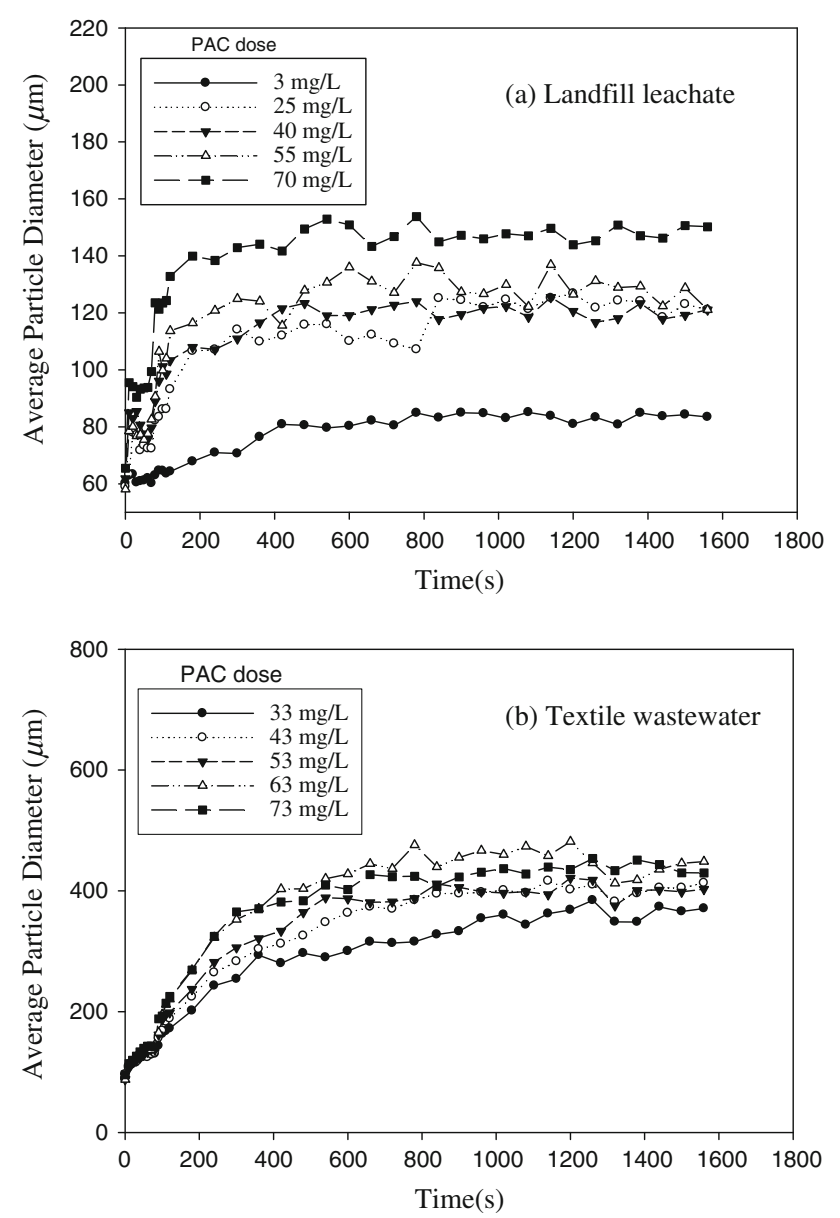

Fig. 4 Typical variations of mean equivalent diameter (ED) of particles during coagulation and flocculation

Significant increases in the total area and total volume of the particles were observed during the initial period of coagulation and flocculation. After $600 \mathrm{~s}$ of flocculation, the measured total area and total volume of the particles were approximately stable. Typically, larger dosages of the PAC coagulant resulted in more significant increases in the total areas and total volumes of both particles, which is consistent with the changes in the mean EDs of the particles.

Measurement of mean fractal dimension of the particles by the DIA method

Fractal dimension $\left(D_{\mathrm{f}}\right)$ is an important factor in particle morphology, and it has been regarded as a key factor that affects the removal efficiency of SS in wastewater treatment (Schmid et al. 2003). The proposed DIA method can easily measure the area and perimeter of each particle in the captured image; thus, the mean fractal dimension of particle can be calculated simultaneously based on the
Area-Perimeter Method (Yu et al. 2009). Figure 6 shows the typical variations of the mean $D_{\mathrm{f}}$ of the particle during coagulation and flocculation. Before coagulation, small particles were dominant in the images; thus, the mean $D_{\mathrm{f}}$ of the particle was relatively small, i.e., around 1.15-1.20. The mean $D_{\mathrm{f}}$ of the particle undergoes a rapid increase during the coagulation period and at the beginning of flocculation; then, after 400-500 s of continuous flocculation, the mean $D_{\mathrm{f}}$ of the particle stabilizes in the range of $1.25-1.30$. Typically, particles with higher mean $D_{\mathrm{f}}$ values contribute in better SS removal efficiencies (Schmid et al. 2003; Yu et al. 2009). In this study, higher mean values of the $D_{\mathrm{f}}$ of the particle typically were found to be associated with the higher PAC dosages added in coagulation and flocculation, which also resulted in better SS removal efficiencies.

\section{Variations of mean gray values of captured images}

Figure 7 shows the typical variations of the mean gray values of the images captured during coagulation and flocculation. A low mean gray value was found at the beginning of coagulation because small particles were dominant in all particle size ranges during this period, which occupy large area in the captured image. The mean gray values of the recorded images increased significantly during the initial period of flocculation, but, after $600 \mathrm{~s}$ of continuous flocculation, the increase in mean gray value became relatively slight. For the coagulation and flocculation of the landfill leachates, the initial mean gray values were around 30-35 units; and they increased to 35-65 units after rapid and slow mixing. Typically, higher final mean gray values of images were found for the samples that had higher PAC dosages. On the other hand, the initial mean gray values of images for the textile wastewaters were around 120-130 units, and they increased to $150-155$ units with a PAC dosage of $58 \mathrm{mg} / \mathrm{L}$. Theoretically, an increase in the mean gray value of an image should occur when the small particles aggregate into larger particles because the larger particles occupy less area than small particles when the masses of the particles are the same. Therefore, a large mean gray value of an image usually is associated with effective removal of the SS in the sample during chemical coagulation and flocculation.

\section{Evaluation of SS removals by ANN model and DIA} data

The measurement of suspended solids is typically based on the total mass of particles in a sample determined by gravimetric analysis, which cannot be conducted on-line. The SS concentrations of wastewater samples can be 

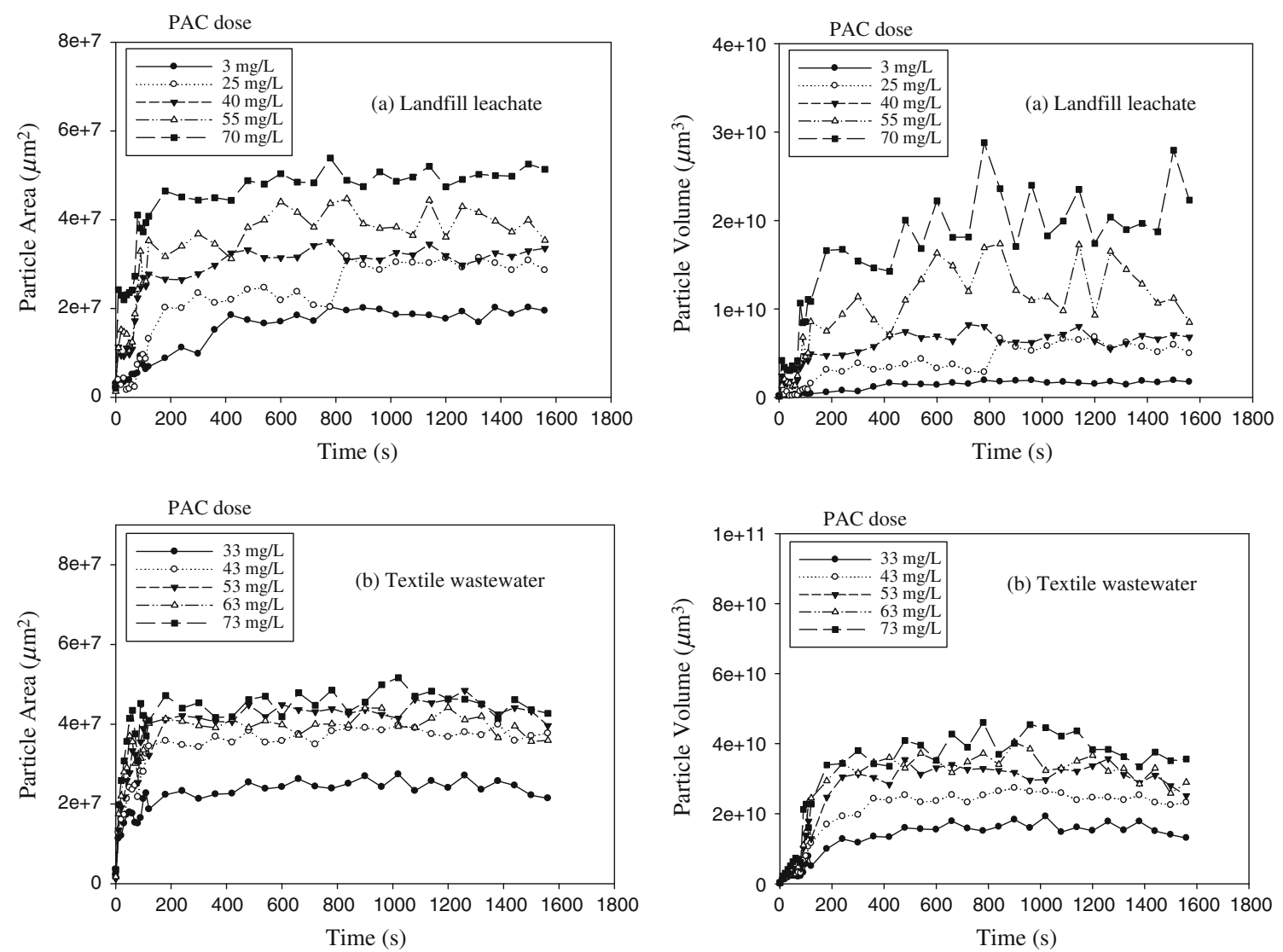

Fig. 5 Typical variations of total area and total volume of particles during coagulation and flocculation

detected on-line by some colorimetric and DIA methods ( $\mathrm{Yu}$ et al. 2009). However, a method to evaluate SS removal is still critically important for the appropriate control of chemical coagulation and flocculation. The removal of SS by chemical coagulation depends on several complex physical and chemical phenomena that are affected by multiple parameters, such as coagulant dosage, particle size distribution, density, and fractal dimension. Therefore, it is difficult to evaluate the removal of SS during coagulation using traditional mathematical models. ANN models are very effective in representing the relationships between input and output variables in complex, nonlinear systems, and they have been applied extensively to address the problems of process forecasting and process control in water and wastewater treatment applications (Zhang and Stanley 1999; Choi and Park 2001; Yu et al. 2010). In this study, ANN models were used to evaluate the SS removal efficiency using on-line DIA monitoring data, including particle size (ED), gray level, total area, total volume, and the fractal dimension.

A typical back-propagation neural network (BPN) model has three layers, i.e., input, hidden, and output layers. The BPN model was developed using PCN4 software and utilized to construct control models. This BPN model uses the generalized delta-learning rule as the training algorithm, the gradient-descent method to minimize error, and root mean square error (RMSE) to evaluate the performance of training and test procedures. For the landfill leachate, two BPN models were used to predict the SS removal efficiencies and the concentrations of SS in the effluent after coagulation and setting; two other BPN models were used to make these determinations for the textile wastewater. Figure 8 shows the architecture of the BPN models proposed in this study, and Table 2 provides detailed information about these BPN models.

The DIA system can simultaneously monitor and calculate five parameters, i.e., the mean size of the particles (ED), the mean gray level, total area of particles, total volume of particles, and the mean fractal dimension of particles $\left(D_{\mathrm{f}}\right)$. According to the experimental results, these five parameters that were measured on-line tend to stabilize after $600 \mathrm{~s}$ of coagulation and flocculation. Using parameter sensitivity analysis, it was found that the 

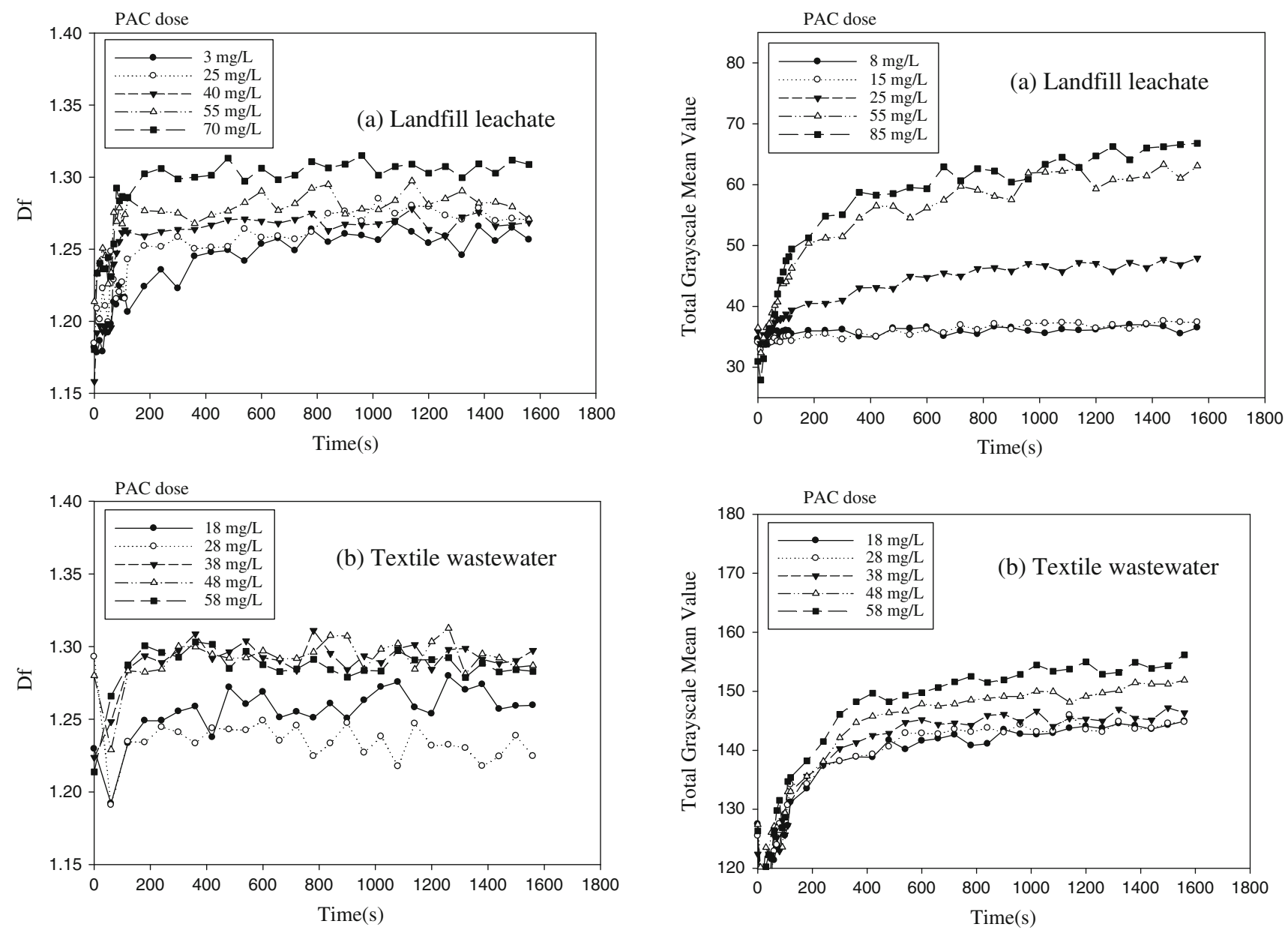

Fig. 6 Typical variations of mean Fractal dimension $\left(D_{\mathrm{f}}\right)$ of particles during coagulation and flocculation

correlation coefficients for SS removal efficiency with average particle size (ED), average gray level, total area of particle, total volume of particle, and average fractal dimension of particle $\left(D_{\mathrm{f}}\right)$ ranged from 0.39 to 0.71 . Therefore, seven input parameters, consisting of mean particle size (ED), mean gray level, total area of particles, total volume of particles, mean fractal dimension of particles $\left(D_{\mathrm{f}}\right)$, PAC dosage, and influent SS concentration, were used in the BPN models as input parameters to predict the SS removal efficiencies and effluent SS concentrations (Table 2). Typically, the stirring velocity or the GT value was regarded as a design parameter not a control parameter in the chemical coagulation. Therefore, the stirring velocity or GT value did not include as one of the input parameters of the ANN models.

For the landfill leachate, 40 data sets were selected randomly from 60 runs of coagulation experimental results as training samples, and the remaining 20 sets were used as test samples in the BPN models. For the textile wastewater

Fig. 7 Typical variations of mean gray values of the images during coagulation and flocculation

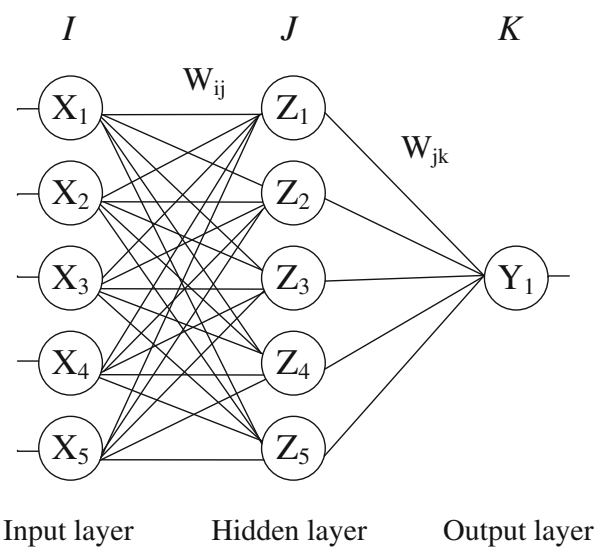

Fig. 8 Architecture of the BPN model used in this study

coagulation experiments, a total of 58 experimental runs were conducted, and 38 of the data sets were selected randomly as training samples, and the remaining 20 sets were used as test samples in the BPN models. 
Table 2 Details of the BPN models in this study

\begin{tabular}{|c|c|c|c|c|c|c|c|c|c|}
\hline \multirow{2}{*}{$\begin{array}{l}\text { BPN } \\
\text { model }\end{array}$} & \multirow[t]{2}{*}{ Input parameter } & \multirow{2}{*}{$\begin{array}{l}\text { Output } \\
\text { parameter }\end{array}$} & \multirow[t]{2}{*}{$R^{2}$} & \multirow{2}{*}{$\begin{array}{l}\text { Network } \\
\text { architecture }\end{array}$} & \multicolumn{5}{|c|}{ Optimization algorithm } \\
\hline & & & & & $\begin{array}{l}\text { Train } \\
\text { cycle }\end{array}$ & $\begin{array}{l}\text { Random } \\
\text { seed }\end{array}$ & $\begin{array}{l}\text { Learn } \\
\text { rate }\end{array}$ & $\begin{array}{l}\text { Train } \\
\text { RMS }\end{array}$ & $\begin{array}{l}\text { Test } \\
\text { RMS }\end{array}$ \\
\hline \multicolumn{10}{|c|}{$B P N$ predictions for real landfill leachate } \\
\hline $\mathrm{BPN}_{1}$ & \multirow{2}{*}{$\begin{array}{l}\text { Average particle size (ED), Average gray level, } \\
\text { total area of particle, total volume of particle, } \\
\text { average fractal dimension of particle }\left(D_{\mathrm{f}}\right), \mathrm{PAC} \\
\text { dose, influent SS concentration }\end{array}$} & $\begin{array}{l}\text { SS removal } \\
\text { efficiency }\end{array}$ & 0.96 & $7-5-1$ & 25,000 & 0.60 & 3.0 & 0.046 & 0.051 \\
\hline $\mathrm{BPN}_{2}$ & & $\begin{array}{l}\text { Effluent SS } \\
\text { concentration }\end{array}$ & 0.97 & $7-5-1$ & 30,000 & 0.70 & 1.0 & 0.029 & 0.039 \\
\hline \multicolumn{10}{|c|}{ BPN predictions for textile wastewater } \\
\hline $\mathrm{BPN}_{3}$ & \multirow{2}{*}{$\begin{array}{l}\text { Average particle size (ED), Average gray level, } \\
\text { total area of particle, total volume of particle, } \\
\text { average fractal dimension of particle }\left(D_{\mathrm{f}}\right), \text { PAC } \\
\text { dose, influent SS concentration }\end{array}$} & $\begin{array}{l}\text { SS removal } \\
\text { efficiency }\end{array}$ & 0.97 & $7-5-1$ & 25,000 & 0.60 & 3.0 & 0.049 & 0.034 \\
\hline $\mathrm{BPN}_{4}$ & & $\begin{array}{l}\text { Effluent SS } \\
\text { concentration }\end{array}$ & 0.93 & $7-5-1$ & 30,000 & 0.70 & 1.0 & 0.028 & 0.055 \\
\hline
\end{tabular}

Where average particle size $(\mu \mathrm{m})$, average gray level $(0-255)$, total area of particle $\left(\mu \mathrm{m}^{2}\right)$, total volume of particle $\left(\mu \mathrm{m}^{3}\right)$, average fractal dimension of particle $\left(D_{\mathrm{f}}\right)$, PAC dose $(\mathrm{mg} / \mathrm{L})$, influent SS concentration $(\mathrm{mg} / \mathrm{L})$

For the coagulation experiments with the landfill leachate, Figure 9 shows the correlations between the SS removal efficiencies predicted by the BPN model and the
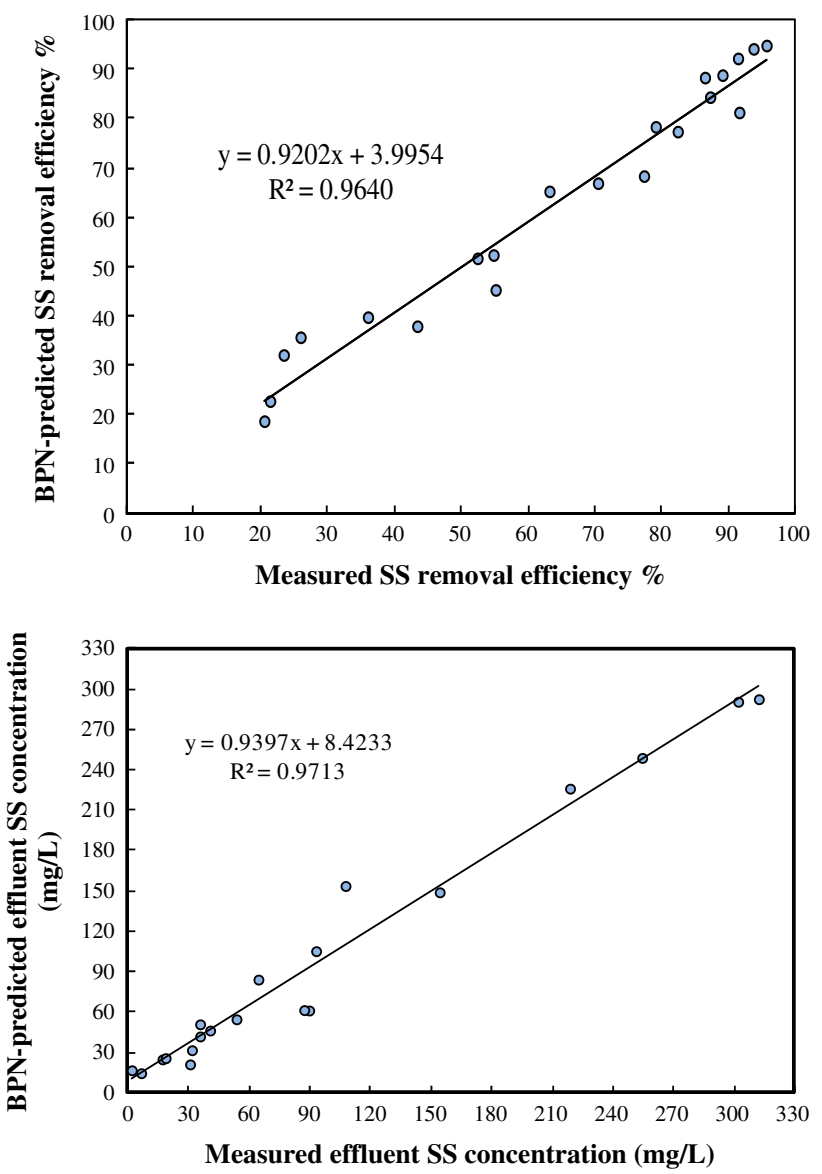

Fig. 9 Correlations between BPN-predicted with measured SS removal efficiencies and effluent SS concentrations for landfill leachate
SS removal efficiencies that were determined experimentally. A very good, linear relationship with an $R^{2}$ of 0.96 was found between the BPN-predicted and the measured
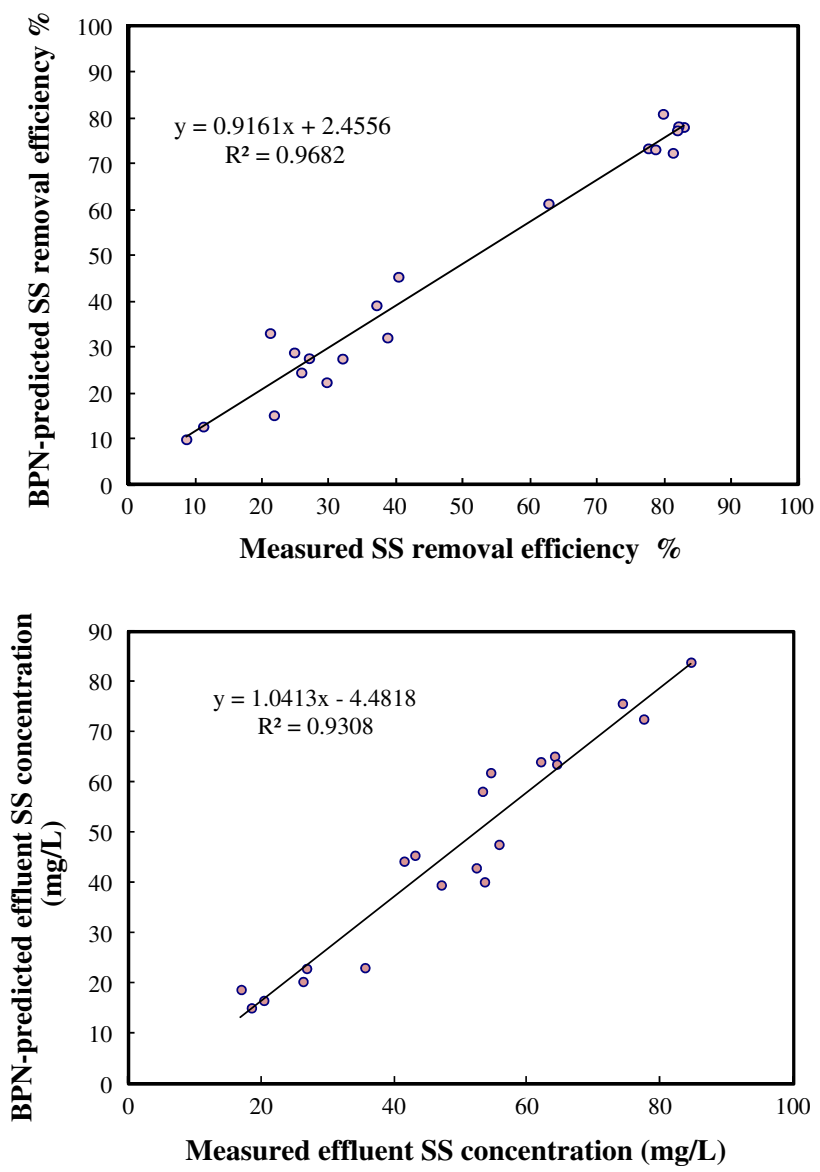

Fig. 10 Correlations between BPN-predicted with measured SS removal efficiencies and effluent SS concentrations for textile wastewater 
SS removal efficiencies. Also, an $R^{2}$ of 0.97 was found between the BPN-predicted and the measured SS concentrations in the effluent of the landfill leachate after chemical coagulation.

Figure 10 shows the correlations between BPN-predicted and measured SS removal efficiencies for the textile wastewater after chemical coagulation. Good linear correlations existed between the BPN-predicted and the measured SS removal efficiencies, with an $R^{2}$ of 0.97 ; also, an $R^{2}$ of 0.93 was found between the BPN-predicted and the measured SS concentrations in the effluent. These results indicate that SS removal efficiencies and SS concentrations in the effluent can be predicted accurately using these BPN models. Also, these findings indicate that SS removal efficiencies and SS concentrations in the effluents of chemical coagulation processes can be determined accurately by these BPN models using the on-line DIA measurement results, which is advantageous for the control of chemical coagulation and flocculation.

\section{Conclusion}

In this study, a novel, on-line approach for evaluating the SS removal in the chemical coagulation was developed using the DIA measurements of particles in conjunction with a BPN model. A high-resolution charge-coupled device was used for the on-line monitoring of the variations of mean equivalent diameter, mean fractal dimension, total area and total volume of particles, as well as the mean gray level of the detected images during the chemical coagulation and flocculation of landfill leachate and textile wastewater. Then, ANN models used the data acquired by monitoring these parameters, along with other operating parameters, including coagulant dosage and the concentration of SS in the influent, to determine the concentration of SS in the effluent and calculate the SS removal efficiencies. The ANN models predicted the SS removal efficiency and effluent SS concentration precisely, with the $R^{2}$ values in the range of $0.93-0.97$. As a result, the use of the proposed ANN model in conjunction with the DIA monitoring provided important information that can be used for controlling and evaluating the effectiveness of particle separation during the chemical coagulation in industrial wastewater treatment processes.

Acknowledgments The authors thank the National Science Council of the Republic of China, Taiwan, for providing financial support for this research under Contract No. NSC-98-2622-E-239-012-CC2.

\section{References}

APHA, AWWA, WEF (2005) Standard methods for the examination of water and wastewater, 21st ed. American Public Health Association, method 2540D, Washington, DC

Burgess MS, Curley JE, Wiseman N, Xiao H (2002) On-line optical determination of floc size. Part I: principles and techniques. J Pulp Paper Sci 28:63-65

Cheng WP, Kao YP, Yu RF (2008) A novel method for on-line evaluation of floc size in coagulation process. Water Res 42:2691-2697

Choi DJ, Park HY (2001) A hybrid artificial neural network as a software sensor for optimal control of a wastewater treatment process. Water Res 35:3959-3967

Govoreanu R, Saveyn H, Van der Meeren P, Vanrolleghem PA (2004) Simultaneous determination of activated sludge floc size distribution by different techniques. Water Sci Tech 50:39-46

Gregory J (1985) Turbidity fluctuation in flowing suspension. J Colloid Interface Sci 105:357-372

Grijspeerdt K, Verstraete W (1997) Image analysis to estimate the settleability and concentration of activated sludge. Water Res 31:1126-1134

Huang CP, Chen GS (1996) Use of the fiber-optical monitor in evaluating the state of flocculation. Water Res 30:2723-2727

Jarvis P, Jefferson B, Parsons SA (2005) Measuring floc structural characteristics. Environ Sci Biotechnol 4:1-18

Kan CC, Huang CP (1998) Coagulation monitoring in surface water treatment facilities. Water Sci Technol 38:237-244

Liao BQ, Droppo IG, Liss SN (2006) Effect of solids retention time on structure and characteristics of sludge flocs in sequencing batch reactor. Water Res 40:2583-2591

McGhee TJ (1991) Water supply and sewerage, 6th edn. McGrawHill, NY, pp 173-201. ISBN: 0-07-100823-3

Merzouk B, Gourich B, Madani K, Vial Ch, Sekki A (2011) Removal of a disperse red dye from synthetic wastewater by chemical coagulation and continuous electrocoagulation, a comparative study. Desalination 272:246-253

Schmid M, Thill A, Purkhold U, Walcher M, Bottero JY, Ginestet P, Nielsen PH, Wuertz S, Wagner M (2003) Characterization of activated sludge flocs by confocal laser scanning microscopy and image analysis. Water Res 37:2043-2052

Snidaro D, Zartarian F, Jorand F, Bottero J-Y, Block J-C, Manem J (1997) Characterization of activated sludge flocs structure. Water Sci Tech 36:313-320

Theepharaksapan S, Chiemchaisri C, Chiemchaisri W, Yamamoto K (2011) Removal of pollutants and reduction of bio-toxicity in a full scale chemical coagulation and reverse osmosis leachate treatment system. Bioresour Technol 102:5381-5388

Veli S, Ozturk T, Dimoglo A (2008) Treatment of municipal solid wastes leachate by means of chemical- and electro-coagulation. Sep Purif Technol 61:82-88

Wilen BM, Balmer P (1999) The effect of dissolved oxygen concentration on the structure, size and size distribution of activated flocs. Water Res 33:391-400

Williams ND, Walling DE, Leeks GJL (2007) High temporal resolution in situ measurement of the effective particle size characteristics of fluvial suspended sediments. Water Res 41:1081-1093

Yu RF, Cheng WP, Chu ML (2005) On-line monitoring of wastewater true color using digital image analysis and ANN. J Environ Eng ASCE 131(1):71-79

Yu RF, Chen HW, Cheng WP, Chu ML (2009) Simultaneously monitoring the particle size distribution, morphology and 
suspended solids concentration in wastewater applying digital image analysis (DIA). Environ Monit Assess 148:19-26

Yu RF, Chen HW, Liu KY, Cheng WP, Hsieh PH (2010) Control of the Fenton process for textile wastewater treatment using artificial neural networks. J Chem Technol Biotechnol $85: 267-278$
Zhang Q, Stanley SJ (1999) Real-time water treatment process control with artificial neural network. J Environ Engrg ASCE 125(2):153-160 